\title{
Quality of Antenatal Care Services at Family Health Units in
}

\author{
Alexandria
}

\author{
Nagwa Y. Abou El-Enein*
}

\begin{abstract}
Background: Quality care encourages health seeking behaviors of clients, motivates health providers, safe guard's client's health and ensures sustainability of the programs, however no adequate data is available on quality of antenatal care in Alexandria. Objective: To assess quality of antenatal care through client satisfaction, provider's performance and availability of basic and necessary equipment in seven selected family health units in Alexandria. Materials and Methods: A cross sectional study was carried out in seven family health units. One health unit was selected randomly from each of the seven administrative zones in Alexandria. Data were collected from clients of the antenatal care service, health providers and the seven health units. For the exit interview, a total of 427 women were selected by proportion to size of clients in each health unit and a structured pre-tested questionnaire was used. All the seven physicians working in the antenatal clinics were observed using observation check list while examining sampled pregnant women. An Observational checklist was used to assess the availability of instruments and medical equipments necessary for antenatal care. Results: Findings indicated poor structure in all the family health units. By observation, $91.3 \%$ of pregnant women received poor care while $8.7 \%$ received fair care. With concern to interpersonal and technical aspects of antenatal care received, $93.9 \%$ and $59.7 \%$ respectively had good level of satisfaction. Regarding constellation of services and continuity of care mechanisms, $90.4 \%$ and $50.1 \%$ of women respectively had fair level of satisfaction, while $54.8 \%$ had poor level of satisfaction with information and counseling. Conclusion: Overall satisfaction of antenatal care is high, although health providers did not follow proper management of the antenatal care service. Recommendations: Family health units should be equipped with essential medical equipments. Regular in-service training of health professionals on use of guidelines for examination and management of women attending antenatal care services is essential.
\end{abstract}

Key words: Antenatal care, family health units, quality

\section{INTRODUCTION}

Antenatal care (ANC) refers to pregnancy

related health care provided by a doctor or a health worker in a health facility or at home. ${ }^{(1)}$

ANC is the key entry point of a pregnant woman to receive broad range of health promotion and preventive services which promote the health of the mother and the baby. ${ }^{(2)}$

Quality of ANC has been designated one of the four Pillars of safe motherhood, along

*Health Administration and Behavioural Sciences Department, High Institute of Public Health 
with clean and safe delivery, essential obstetric care and family planning which could contribute to reduction of maternal mortality. ${ }^{(3,4)}$ While poor access to basic antenatal care is recognized as a major obstacle to improvement in pregnancy outcomes, there is a growing consensus that access to antenatal care alone is insufficient to alter the present maternal health profile and that the quality of antenatal services may be a key determinant of maternal and perinatal outcomes. $^{(5)}$

Quality health care means providing health services to individuals and communities to improve health outcomes which should be compatible with the new professional knowledge. Quality antenatal care implies the extent to which antenatal care resources and services correspond with antenatal standards of a particular country. ${ }^{(6)}$ To provide quality ANC, the health care providers need to have adequate infrastructure, clinical skills, necessary equipment and supplies and the referral system should function well enough that women with complications get treatment as soon as possible. The care provided should be sensitive to women's and their family's needs and should be satisfactory. ${ }^{(7)}$

Quality of ANC depends on how women attend, initiate antenatal visits at a health facility. ${ }^{(8)}$ Quality requires that pregnant women attend ANC as early as possible to receive the necessary care. ${ }^{(7)}$ According to UICEF/WHO, about $70 \%$ of women worldwide had at least one antenatal visit with a skilled provider during pregnancy. ${ }^{(8)}$ In Egypt, during the 5 years prior to the 2008 Egyptian Demographic Health Survey, antenatal care coverage for at least one visit was $74 \%$ and antenatal care coverage for at least four visits was $66 \%{ }^{(9)}$

Quality can be assessed based on the point of view of the users (perceived quality) or by using technical standards (quality defined by professionals). ${ }^{(10,11)}$ Donabedian was one of the first to reflect upon quality, to operationalize the term, and to offer a framework for its definition based on three 
major attributes: structure, process, and outcome. ${ }^{(10)}$ "Structure" refers to the attributes of the settings where health care occurs (material, human and financial resources, and organizational structure); "process" denotes what is actually done in giving and receiving care; and "outcome" indicates the effects of care on the health status of patients and populations (morbidity and mortality levels). Most studies assessing quality of care have looked at curative services and at structural aspects and process attributes, ${ }^{(12-14)}$ at client satisfaction, ${ }^{(15,16)}$ or at the relation between curative and preventive services. ${ }^{(17)}$

Recent studies in Alexandria about the quality of antenatal care services at family health units which represent a primary care level are lacking. This study was designed to assess the quality of antenatal care services provided in the family health units in Alexandria. This can act as a starting point for improvement in the quality of antenatal care at this level of health care delivery by providing useful information to researchers and policy makers in this environment.

Within this context, this study aimed to identify availability of resources required for providing ANC, to assess providers' practice in providing ANC and to explore women's satisfaction with the quality of antenatal services received.

\section{MATERIALS AND METHODS}

\section{Study setting:}

The study was conducted in 7 family health units in Alexandria; one unit was randomly selected from each of the seven administrative regions in Alexandria (Shark, Gharb, Elmontazah, Elgomrok, Elamreia, Wassat, and Borg- Elarab). Family health units are affiliated to and operated by Ministry of Health and provide health care to insured and non insured patients.

\section{Study design:}

\section{Descriptive cross-sectional study}

\section{Study population}

The study included the following:

1. A sample of family health units to assess the structure of care. 
2. All the family health physicians who work in the selected units during the study period to assess the process of care, excluding those who are in sick leave or vacation, the total was 7 physicians.

3. A sample of pregnant women (clients) who have had at least one antenatal visit to one of the selected units to assess their satisfaction with the various aspects of quality of antenatal care received (outcome of care).

\section{Sampling size and process:}

1. A sample of family health units was selected to assess the structure of care. One unit was randomly selected from each of the seven administrative zones in Alexandria. The total was seven units. The researcher randomly selected one health unit from the seven units, then selected one day from six working days of the week to start visiting each unit. The researcher visited each unit on consecutive days until the estimated sample was reached.
2. All the family health physicians who work in the selected units during the study period were included to assess the process of care with exclusion of those who were in sick leave or vacation, the total was 7 physicians. The researcher observed family health physicians while providing antenatal care for a sample of pregnant women $(n=427)$ before conduction of exit interview with them to assess their satisfaction (the total number of observations was 427). All the physicians accepted to participate in the study.

3. A sample of pregnant women (clients) who have had at least one antenatal visit at the study setting to assess their satisfaction with the various aspects of quality of antenatal care received (outcome of care) was estimated as follows:

The minimum sample size required for the study was estimated to be 384 using the formula $n=\mathrm{p}(1-\mathrm{p})\left(Z_{-} / \mathrm{d}\right) 2$ where $n$ is the 
sample size, $Z_{-}$is the standard normal deviate, set at 1.96 (for 95\% confidence level), $d$ is the desired degree of accuracy (taken as 0.05 ) and, $p$ is the estimate of the satisfaction rate among our target population (which was assumed to be $50 \%$ in the absence of a preexisting estimate). ${ }^{(15)}$ The sample was raised to 427 to adjust non-responses. To achieve the desired sample size for the study, the available statistics at each unit was used to estimate the average number of pregnant women seen during each antenatal clinic at each unit and the number of pregnant women selected from each unit was determined by a proportional allocation ratio method, i.e. the total number of women sampled from each unit was in accordance with the relative proportion of its weekly antenatal clinic's population. Women at each unit were selected by random sampling method until the estimated sample size for the unit was achieved.

The study was conducted during a period of 3 months starting from March to June 2010.
On each of the days of the study; the researcher enrolled the women as per the number required for that health unit. During the study period, the researcher visited the female waiting area of the antenatal clinics. The purpose of the study was explained to waiting expectant mothers and asked for voluntary participation, and obtained their verbal consent to participate. They were informed about their rights to withdraw at any time. Total confidentiality of any obtained information was assured. The interview was conducted at the time of exit using a structured and pre-tested questionnaire. There were no pregnant women who refused the interview. After finishing observation of physicians while providing the process of care for the pregnant woman, the researcher interviewed the same woman for approximately 15 to 20 minutes in an area with adequate confidentiality and privacy and without any involvement of health care providers. The area is away from the antenatal clinics to avoid influence of 
healthcare providers.

Data collection techniques and tools:

The study was based on the conceptual and analytic framework of quality which was developed by Donabedian ${ }^{(10)}$ The framework uses three elements of quality (structure, process and outcome).

\section{Assessment of structure}

A checklist was used to assess structural items. Its design was based on literature review. $^{(18,19)}$ Scoring of individual items of structure was done, it was a weighted score and based on literature review. ${ }^{(19)}$ It was based on a professional judgment on what can be considered as a good medical or behavioural standard. The checklist included general infrastructure, basic diagnostic equipment available, maintenance of facility and drugs available.

Level of the structure was classified according to the total maximum score (51 points) into the following grades:

- Good level of structure $>80 \%$ (score $>40.8)$
- Fair level of structure from $60 \%$ to $<80 \%(30.6-40.8)$

- Poor level of structure $<60 \%$ (score $<30.6$ )

\section{Assessment of process}

The process was measured through observation checklist. Scoring of individual items of process was done; it was a weighted score and based on professional judgment and literature review. ${ }^{(19)}$ The researcher observed family health physicians while providing antenatal care to the study sample (427 pregnant women). The checklist (including scores) covered two aspects of care: interpersonal and technical aspects.

Level of the process was classified according to the total maximum score (54 points) into the following grades:

- Good level of process > 80\% (>43.2)

- Fair level of process from $60 \%$ to $<80 \%$ $(32.4-43.2)$

- Poor level of process $<60 \%$ ( $<32.4)$

\section{Assessment of outcome}

Outcome in this study included women's satisfaction with care received at the health 
facility. Interviewing was the data collection technique. The tool was a structured questionnaire which is based on literature review. $^{(5,16,20,21)}$ The questionnaire included some characteristics of clients, dimensions of satisfaction as technical quality of care, continuity of care mechanisms and provision of choices, information and counseling, constellation of services, client-provider interpersonal relationships. To assess women's overall satisfaction with the quality of antenatal care, the summary section of the questionnaire contained three indicators employed by WHO to summarize women's overall perception in the antenatal care trial. ${ }^{(22)}$ These indicators included one direct and two indirect summary questions asked against the background of women's responses to previous enquiries on the various aspects of antenatal care quality. It was expected that this "overall satisfaction" variable would reflect women's overall perception of the quality of antenatal care received. ${ }^{(23)}$ This variable was determined by respondents' affirmative answers to these three questions: "if you were pregnant again, would you come back to this clinic?", "would you recommend this clinic to a relative or a friend for their antenatal checkups?" and "in general, are you satisfied with antenatal care you have received so far in this clinic?" For the purpose of this study, an affirmative answer to all of the three questions by respondent was considered an index of true satisfaction with the quality of antenatal care received. For testing the tool, the questionnaire was pretested among 25 women receiving antenatal care at one of the sampled units of the study area. No modification was required and the results were not used in the study.

\section{Scoring of outcome:}

As close-ended questionnaire was prepared to collect responses, each question had five grades of response. The scores were marked using a 5-point Likert scale, ${ }^{(9)}$ in descending order $(0,1,2,3,4)$, as follows: fully satisfied (4 points), somewhat satisfied (3 points), neither satisfied nor dissatisfied 
(equivocal) (2 points), somewhat dissatisfied (1 point) and dissatisfied (zero point). The mean score percent for each item was computed by multiplying the number of respondents in fully satisfied level by 4 , in somewhat satisfied level by 3 and so on then, adding the resulting three figures and dividing the sum by the total number of respondents. The resulting figure which may range between 0 and 4 was then divided by 4 and multiplied by 100 to convert the score into percentage.

The mean score percent for each dimension was computed as the sum of mean score percent of all items of a specific dimension divided by the numbers of items of that dimension. The dimension score percent ranged from 0.0 to $100 \%$. Level of overall satisfaction was classified according to overall satisfaction mean score percent of the dimension into the following grades:

- Good level of satisfaction from 80 to $100 \%$

- Fair level of satisfaction from 50 to $<80 \%$

- Poor level of satisfaction $<50 \%$

\section{Ethical Considerations}

The $\mathrm{MOH}$ permission was obtained to conduct the survey. The purpose, general content and nature of the investigation were explained to each respondent to obtain verbal consent before inclusion into the study.

\section{Statistical analysis:}

The data was computed using EPI Data. The frequency and percentage proportions were calculated using the Statistical Package for Social Studies (SPSS), Version 16.

\section{Study Limitations:}

One limitation of this study was lack of literature on quality ANC relevant to Egypt in general and Alexandria in particular. The other limitation was that the study findings cannot be generalized to other organizations. However, the findings have provided strong baseline data for planners and implementers of the reproductive health services in coming up with strategies for improving the quality of antenatal care. Another important limitation of 
this study was the lack of qualitative exploration of women's views and expectations, which did not permit one to know which aspect of quality best determines their satisfaction. It should be realized, however, that while qualitative methods allow women to disclose their feelings in greater depth than quantitative research methods, their low external validity limits applicability of the findings to the population from which the study sample was drawn.

\section{RESULTS}

Table 1 shows score of the structure of family health units. The total score for structure of the seven family health units was less than $60 \%$ of total score, reflecting poor structure in all the family health units. There were deficiencies of the structure items in the units but in a variable degree.

Table 1. Score of the structure of family health unit

\begin{tabular}{|c|c|c|c|c|c|c|c|}
\hline \multirow[t]{2}{*}{ Structure items } & \multicolumn{7}{|c|}{ Family Health Units } \\
\hline & Unit 1 & Unit 2 & Unit 3 & Unit 4 & Unit 5 & Unit 6 & Unit 7 \\
\hline \multicolumn{8}{|l|}{ General infrastructure: (3 points each) } \\
\hline Toilets with water & 0 & 0 & 0 & 0 & 0 & 0 & 0 \\
\hline waiting area & 3 & 3 & 3 & 3 & 3 & 3 & 3 \\
\hline privacy of examination room & 3 & 3 & 3 & 3 & 3 & 3 & 3 \\
\hline water to wash hands & 3 & 3 & 3 & 3 & 3 & 3 & 3 \\
\hline \multicolumn{8}{|l|}{$\begin{array}{l}\text { Basic diagnostic equipment available: } \\
\text { ( } 3 \text { points each) }\end{array}$} \\
\hline Sphygmomanometer & 0 & 0 & 0 & 0 & 0 & 3 & 0 \\
\hline Microscope & 3 & 3 & 3 & 3 & 3 & 3 & 3 \\
\hline Gloves & 3 & 3 & 0 & 3 & 3 & 3 & 3 \\
\hline Stethoscope & 3 & 3 & 3 & 3 & 3 & 3 & 3 \\
\hline Scale & 0 & 0 & 0 & 3 & 0 & 0 & 0 \\
\hline Laboratory & 3 & 3 & 3 & 3 & 3 & 3 & 3 \\
\hline Haemoglobin measurement & 0 & 0 & 3 & 0 & 0 & 0 & 0 \\
\hline Uristix for the detection of glucose & 0 & 0 & 3 & 0 & 0 & 0 & 0 \\
\hline Protein in the urine & 0 & 0 & 3 & 0 & 0 & 0 & 0 \\
\hline \multicolumn{8}{|l|}{ Maintenance of facility: ( 3 points each) } \\
\hline Cleanliness of toilets and facility & 0 & 0 & 0 & 0 & 0 & 0 & 0 \\
\hline Maintenance of floors and walls & 0 & 0 & 0 & 0 & 0 & 0 & 0 \\
\hline \multicolumn{8}{|l|}{ Drugs available: (2 points each) } \\
\hline Iron sulphate & 3 & 0 & 0 & 0 & 0 & 0 & 0 \\
\hline Folic acid & 3 & 0 & 0 & 0 & 0 & 0 & 0 \\
\hline Tetanus toxoid vaccination & 3 & 0 & 3 & 0 & 0 & 0 & 0 \\
\hline Total & 30 & 21 & 30 & 24 & 21 & 24 & 21 \\
\hline Mean score percent (total score $=51$ ) & 58.8 & 41.2 & 58.8 & 47.1 & 41.2 & 47.1 & 41.2 \\
\hline
\end{tabular}


Table 2 demonstrates score of the process of antenatal care in the family health units. Regarding overall degree of care, $91.3 \%$ of pregnant women received poor care and $8.7 \%$ received fair care. Regarding individual items of process, asking about woman's concerns, privacy (door closed during consultation), explaining procedures to the women before examination, explaining the diagnosis and use of prophylactic drugs, assessing the history of women, checking eyes, urine for infection and legs for oedema were all not done for any woman (100\%). Checking weight and fetal heart sound, providing general health education and nutritional education were all done for about ninety percent of women (90.6\%). Provision of prophylactic iron sulphate, folic acid and tetanus toxoid were not done for $25.5 \%$ of women while blood pressure measurement, checking hemoglobin and urine for albumin were not done for $23.9 \%$ of women.
Table 3 demonstrates some characteristics of a sample of pregnant women who were attending family health units. The highest percent of women (41.0\%) was below 25 years and mean age was $28.1 \pm 6.438$. More than half of women (58.3\%) had primary education while over ninety percent were unemployed and from inside the family health unit catchment area $(95.8 \%$ and 93.2 respectively). Nearly fifty percent of the women $(48.0 \%)$ were pregnant three times before the current pregnancy. Out of those who were pregnant before (287 women), $52.3 \%$ had three or more children. The gestation age of $67.2 \%$ of women was below 37 weeks and $83.8 \%$ of women had at least two antenatal care visits (all the women were in the third trimester i.e. $27-42$ week), $62.3 \%$ previously used the unit for ANC. The table also reveals that the mean waiting time was $1.4 \pm 0.814$. 
Table 2. Score of the process of antenatal care in family health units

\begin{tabular}{|c|c|c|c|c|}
\hline \multirow[t]{2}{*}{ Process of care } & \multicolumn{2}{|c|}{ Performed } & \multicolumn{2}{|c|}{ Not Performed } \\
\hline & No. & $\%$ & No. & $\%$ \\
\hline \multicolumn{5}{|l|}{ Interpersonal aspects: (Maximum, 16 points): } \\
\hline Seat offered (2 points) & 427 & 100 & 0 & 0 \\
\hline \multicolumn{5}{|l|}{ Health worker-woman interaction } \\
\hline Interest (2 points) & 389 & 91.1 & 38 & 8.9 \\
\hline Non-interruption of woman's speech (1 point) & 315 & 73.8 & 112 & 26.2 \\
\hline Politeness(2 points) & 407 & 95.3 & 20 & 4.7 \\
\hline Asking about woman's concerns (2 points) & 0 & 0 & 427 & 100.0 \\
\hline \multicolumn{5}{|l|}{ Privacy } \\
\hline $\begin{array}{l}\text { Door closed during consultation (1 point) } \\
\text { Explaining procedures }\end{array}$ & 362 & 84.8 & 65 & 65 \\
\hline Before examination (2 points) & 0 & 0 & 427 & 100.0 \\
\hline Explaining diagnosis(2 points) & 0 & 0 & 427 & 100.0 \\
\hline Explaining use of prophylactic drugs (2 points) & 0 & 0 & 427 & 100.0 \\
\hline \multicolumn{5}{|l|}{$\begin{array}{l}\text { Technical aspect ( Maximum, } 38 \text { points): } \\
\text { Assessing the history of }\end{array}$} \\
\hline Any problem (3 points) & 0 & 0 & 427 & 100.0 \\
\hline Urinary tract infection (2 points) & 40 & 9.4 & 387 & 90.6 \\
\hline \multicolumn{5}{|l|}{ Diagnostic approach } \\
\hline Blood pressure measurement ( 3 points) & 325 & 76.1 & 102 & 23.9 \\
\hline checking haemoglobin (3 points) & 325 & 76.1 & 102 & 23.9 \\
\hline checking urine for albumin (2 points) & 325 & 76.1 & 102 & 23.9 \\
\hline $\begin{array}{l}\text { checking urine for infection (2 points) } \\
\text { Prophylactic drugs }\end{array}$ & 0 & 0 & 427 & 100.0 \\
\hline $\begin{array}{l}\text { Provision of prophylactic drugs Iron(II) sulfate ( } 3 \\
\text { points) }\end{array}$ & 318 & 74.5 & 109 & 25.5 \\
\hline $\begin{array}{l}\text { Provision of prophylactic drugs folic acid ( } 3 \text { points) } \\
\text { Vaccination }\end{array}$ & 318 & 74.5 & 109 & 25.5 \\
\hline Provision of tetanaus toxoid ( 3 points) & 318 & 74.5 & 109 & 25.5 \\
\hline \multicolumn{5}{|l|}{ Physical examination } \\
\hline Checking eyes (2 points) & 0 & 0 & 427 & 100.0 \\
\hline Checking Legs For Oedema (3 Points) & 0 & 0 & 427 & 100.0 \\
\hline Checking Weight (2 Points) & 40 & 9.4 & 387 & 90.6 \\
\hline Checking Foetal Heart Sound (3 Points) & 318 & 74.5 & 109 & 25.5 \\
\hline \multicolumn{5}{|l|}{ Providing health education } \\
\hline General health education (2 points) & 40 & 9.4 & 387 & 90.6 \\
\hline Nutritional education (2 points) & 40 & 9.4 & 387 & 90.6 \\
\hline Degree of care (54 points) & & $(n=427$ & & $(\%)$ \\
\hline Good $(\geq 43.2)$ & & 0 & & 0 \\
\hline Fair $(32.4-43.2)$ & & 37 & & 8.7 \\
\hline Poor $(<32.4)$ & & 390 & & 91.3 \\
\hline
\end{tabular}


Table 3. Some characteristics of a sample of pregnant women attending family health units

\begin{tabular}{|c|c|}
\hline Characteristics & $\begin{array}{l}(n=427) \\
\text { No. (\%) }\end{array}$ \\
\hline \multicolumn{2}{|l|}{ Age } \\
\hline$<25$ & $175(41.0)$ \\
\hline $25-$ & 91 (21.3) \\
\hline $30-$ & $63(14.8)$ \\
\hline $35+$ & $98(22.9)$ \\
\hline Mean \pm SD & $28.1 \pm 6.438$ \\
\hline \multicolumn{2}{|l|}{ Education } \\
\hline None & $152(35.6)$ \\
\hline Primary & $249(58.3)$ \\
\hline Secondary & $22(5.2)$ \\
\hline University & $4 \quad(0.9)$ \\
\hline \multicolumn{2}{|l|}{ Occupation } \\
\hline Unemployed & $409(95.8)$ \\
\hline Employed & $18(4.2)$ \\
\hline \multicolumn{2}{|l|}{ Residence } \\
\hline Inside unit catchments area & $398(93.2)$ \\
\hline Outside unit catchments area & $29(6.8)$ \\
\hline \multicolumn{2}{|l|}{ Parity } \\
\hline Nulliparous & $140(32.8)$ \\
\hline $1-$ & $82(19.2)$ \\
\hline $3+$ & $205(48.0)$ \\
\hline \multicolumn{2}{|l|}{ Children number $(n=287$ ) } \\
\hline 1 & $13(4.5)$ \\
\hline 2 & $124(43.2)$ \\
\hline $3+$ & $150(52.3)$ \\
\hline \multicolumn{2}{|l|}{ Gestational age } \\
\hline$<37$ & $287(67.2)$ \\
\hline $37-40$ & $98(23.0)$ \\
\hline$>40$ & $42(9.8)$ \\
\hline \multicolumn{2}{|l|}{ Number of ANC visits } \\
\hline 2 & $358(83.8)$ \\
\hline 3 & $37(8.7)$ \\
\hline 4 & $24(5.6)$ \\
\hline 5 & $8(1.9)$ \\
\hline \multicolumn{2}{|l|}{ Previously used unit for ANC } \\
\hline Yes & $266(62.3)$ \\
\hline No & $161(37.7)$ \\
\hline \multicolumn{2}{|l|}{ Waiting time in minutes } \\
\hline $120-$ & $67(15.7)$ \\
\hline $150-$ & $58(13.6)$ \\
\hline $180+$ & $302(70.7)$ \\
\hline Mean \pm Standard deviation & $1.4 \pm 0.814$ \\
\hline
\end{tabular}


Table 4 illustrates level of satisfaction with different items of the five dimensions of antenatal care. Concerning technical aspect of care, the highest percent of women (which is over fifty percent) had good level of satisfaction with all the items of technical care. Regarding continuity of care mechanisms and provision of choices, all the women (100\%) had good level of satisfaction with information about the timing of their next visit. On the other hand, all the women (100\%) had poor level of satisfaction with gender of provider and availability of reminder system. Regarding continuity of provider, the right to seek another doctor and women's involvement with decision-making with respect to care, $47.3 \%$ of women had poor level of satisfaction. Concerning interpersonal aspects of antenatal care received, over eighty percent of women had good level of satisfaction with treatment with respect, protection of their privacy and treating them equally. With respect to information and counseling, the highest percent of women (95.1\%) had poor level of satisfaction. From the table, it appears that $97.0 \%$ had good level of satisfaction with frequency and spacing of their antenatal visits belonged to the dimension of constellation of services. In addition, the highest percent of women; $83.1 \%, 83.5 \%$ and $81.8 \%$ had poor -level of satisfaction with waiting time, toilet facility and waiting room respectively. On the other hand, $85.0 \%$ and $81.7 \%$ of women had good level of satisfaction with examination room and working days respectively. About, one fourth of women $(25.3 \%)$ had poor level of satisfaction with drugs and supply at the units. 
Table 4. Level of satisfaction with items of the five dimensions of antenatal care

\begin{tabular}{|c|c|c|c|c|c|c|}
\hline \multirow{3}{*}{ Dimensions of satisfaction } & \multicolumn{6}{|c|}{$\begin{array}{l}\text { Level of Satisfaction } \\
(n=427)\end{array}$} \\
\hline & \multicolumn{2}{|c|}{ Poor } & \multicolumn{2}{|c|}{ Fair } & \multicolumn{2}{|c|}{ Good } \\
\hline & No. & $\%$ & No. & $\%$ & No. & $\%$ \\
\hline \multicolumn{7}{|l|}{ Technical aspect of the care } \\
\hline Number of visits & 109 & 25.5 & 32 & 7.5 & 286 & 67.0 \\
\hline Level of expertise as reported by ANC providers & 121 & 28.3 & 67 & 15.7 & 239 & 56.0 \\
\hline Visit of the general family medicine physician & 130 & 30.4 & 51 & 11.9 & 246 & 57.6 \\
\hline $\begin{array}{l}\text { Care providers could effectively handle minor } \\
\text { obstetric complications }\end{array}$ & 133 & 31.1 & 31 & 7.3 & 263 & 61.6 \\
\hline Vaccination against tetanus & 52 & 12.2 & 0 & 0.0 & 375 & 87.8 \\
\hline \multicolumn{7}{|l|}{$\begin{array}{l}\text { Continuity of Care Mechanisms and Provision of } \\
\text { Choices }\end{array}$} \\
\hline Continuity of provider & 202 & 47.3 & 31 & 7.3 & 194 & 45.4 \\
\hline Information about the timing of their next visit & 0 & 0.0 & 0 & 0.0 & 427 & 100.0 \\
\hline Individual antenatal records & 14 & 3.3 & 63 & 14.8 & 350 & 82.0 \\
\hline Gender of provider & 427 & 100.0 & 0 & 0.0 & 0 & 0.0 \\
\hline The right to seek another doctor. & 202 & 47.3 & 31 & 7.3 & 194 & 45.4 \\
\hline Availability of reminder system & 427 & 100.0 & 0 & 0.0 & 0 & 0.0 \\
\hline Involvement with decision-making related to care & 202 & 47.3 & 31 & 7.3.0 & 194 & 45.4 \\
\hline \multicolumn{7}{|l|}{ interpersonal aspects of antenatal care received } \\
\hline Treated you with respect & 20 & 4.7 & 18 & 4.2 & 389 & 91.1 \\
\hline Protected your privacy & 19 & 4.4 & 46 & 10.8 & 362 & 84.8 \\
\hline Treated you equally like other clients & 34 & 8.0 & 24 & 5.6 & 369 & 86.4 \\
\hline Carried out unnecessary procedure/examination & 0 & 0.0 & 0 & 0.0 & 427 & 100.0 \\
\hline Treated you with empathy & 79 & 18.5 & 35 & 8.2 & 313 & 73.3 \\
\hline \multicolumn{7}{|l|}{ Information and Counseling } \\
\hline information provided by their caregivers & 213 & 49.9 & 0 & 0.0 & 214 & 50.1 \\
\hline Health education & 406 & 95.1 & 0 & 0.0 & 21 & 4.9 \\
\hline \multicolumn{7}{|l|}{ Constellation of Services } \\
\hline Frequency and spacing of their antenatal visits & 0 & 0.0 & 13 & 3.0 & 414 & 97.0 \\
\hline Spent enough time with you during consultation & 213 & 49.9 & 0 & 0.0 & 214 & 50.1 \\
\hline Waiting time & 355 & 83.1 & 62 & 14.5 & 10 & 2.3 \\
\hline Waiting room/area & 358 & 83.8 & 65 & 15.2 & 4 & 0.9 \\
\hline Examination room & 48 & 11.2 & 16 & 3.7 & 363 & 85.0 \\
\hline Toilet facility & 348 & 81.5 & 61 & 14.3 & 18 & 4.2 \\
\hline Drugs and supply at the unit & 108 & 25.3 & 1 & 0.2 & 318 & 74.5 \\
\hline Costs of services & 132 & 30.9 & 0 & 0.0 & 295 & 69.1 \\
\hline Service hours & 85 & 19.9 & 26 & 6.1 & 316 & 74.0 \\
\hline Working days & 70 & 16.4 & 8 & 1.9 & 349 & 81.7 \\
\hline Distance to clinic & 65 & 15.2 & 24 & 5.6 & 338 & 79.2 \\
\hline
\end{tabular}

Figure 1 shows level of satisfaction with

the five dimensions of antenatal care.

Regarding interpersonal aspects of antenatal care received and technical aspect of care, the highest percent of women had good level of satisfaction 
$(93.9 \%$

$$
\text { and }
$$

$59.7 \%$

respectively).

satisfaction

$(90.4 \%$

and

$50.1 \%$

Regarding constellation of services and respectively). Regarding information and continuity of care mechanisms, the highest counseling, the highest percent of women percent of women had fair level of $(54.8 \%)$ had poor level of satisfaction.

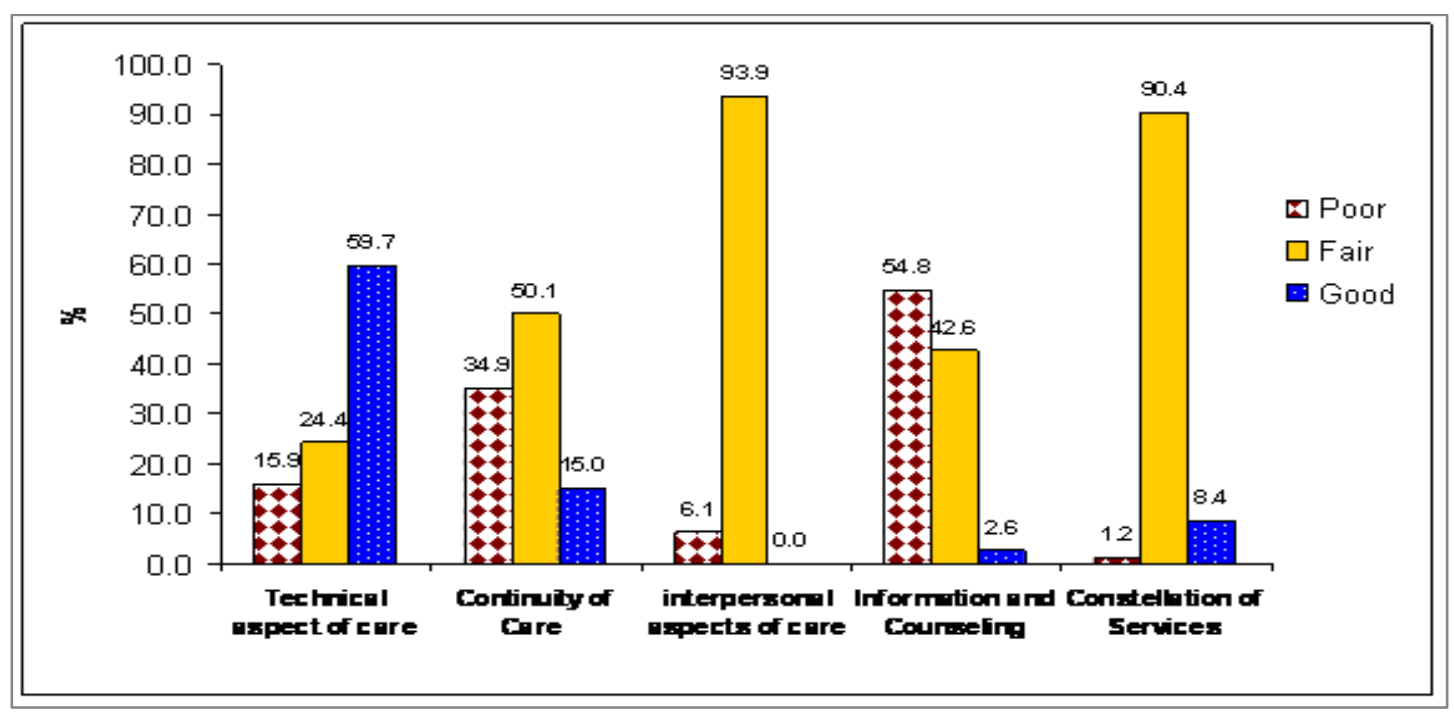

Figure 1. Level of satisfaction with the five dimensions of antenatal care

Table 5 shows relation between mean satisfaction score percent of the different dimensions of antenatal care and selected characteristics of the pregnant women. There is statistically significant relation between the "technical aspect of care" dimension and parity and previously using the unit $(p=0.027)$; the "constellation of service" dimension and occupation, residence, and waiting time in minutes $(p=0.000)$; the "Interpersonal relation" dimension and age and occupation ( $p=0.017$ and 0.040 respectively); the "continuity of care" dimension and age $(p=0.003)$ and the "information given" dimension and education $(p=0.018)$. There is no statistically significant relation between any dimension and children number, gestational age or number of ANC visit 
Table 5. Relation between mean satisfaction score percent of the different dimensions of antenatal care with selected characteristics of the pregnant women

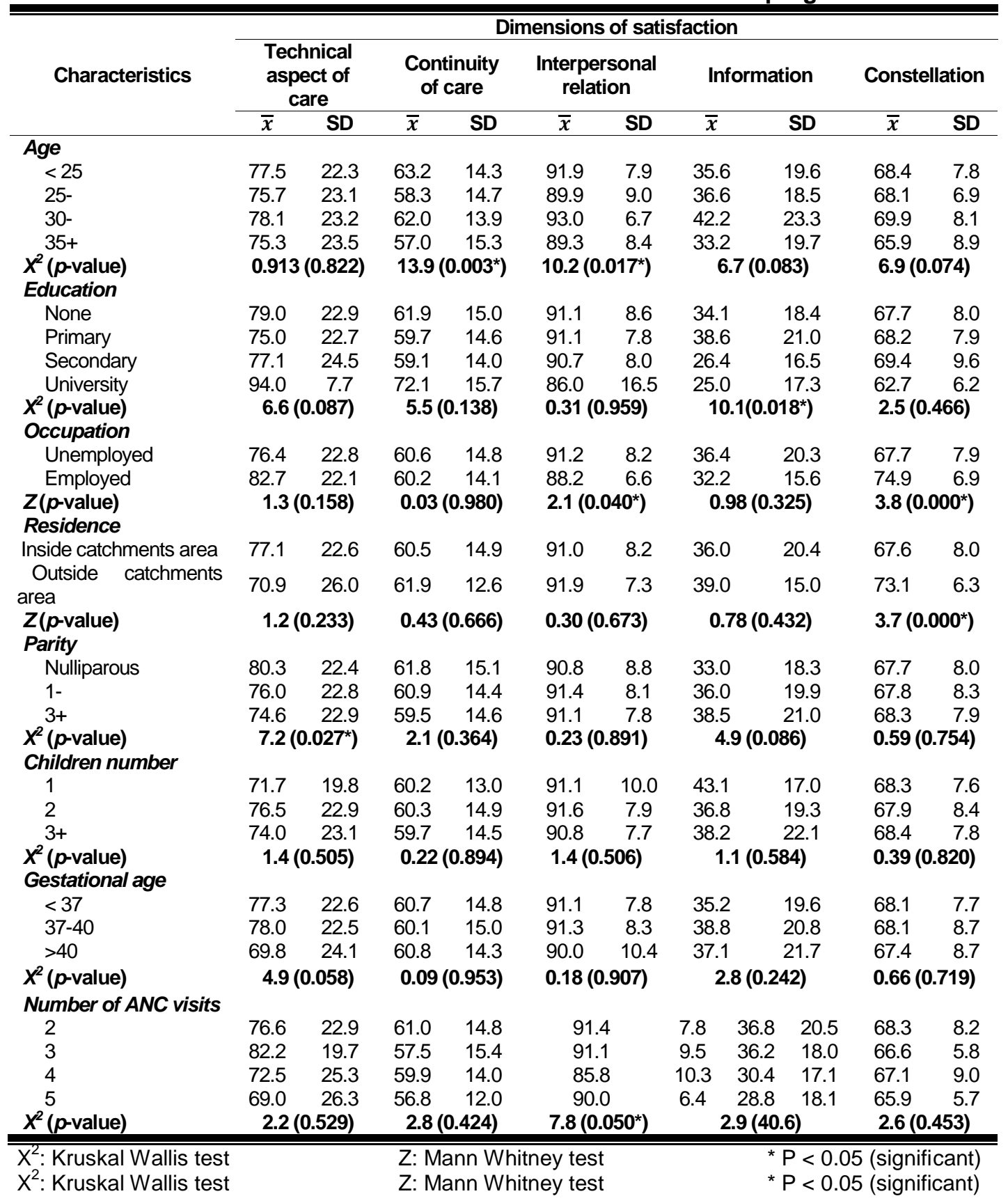


Figure 2 demonstrates pregnant women's overall satisfaction in general and intention to visit the unit again or recommend it to others. Over fifty percent $(57.1 \%)$ of the the service. sample mentioned that they will visit the unit again and recommend it to others while $70.3 \%$ were in general satisfied with

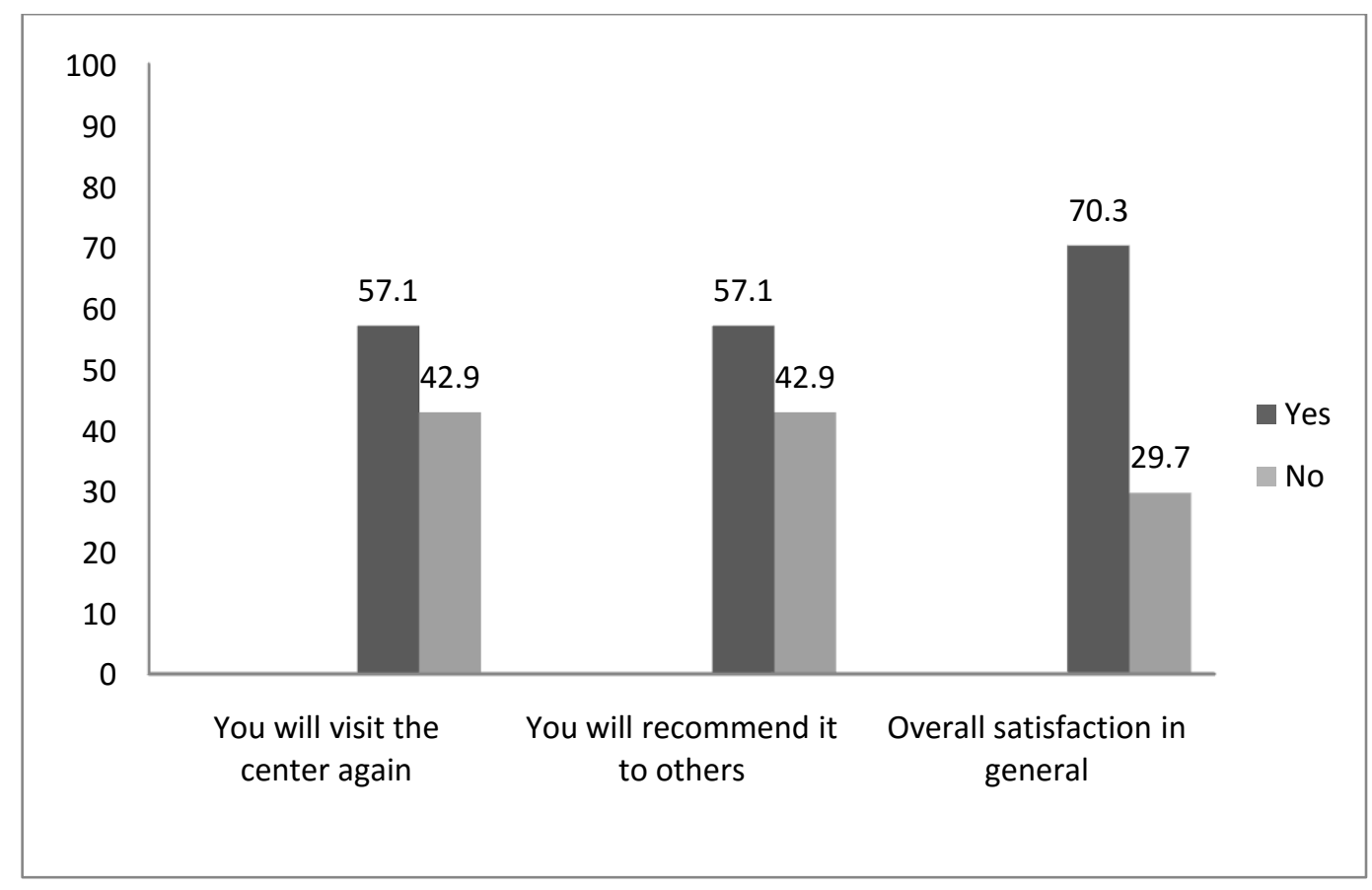

Figure 2. Pregnant women's overall satisfaction in general and intention to visit the unit again or recommend it to others

Table 6 reveals stepwise linear and the total satisfaction score of the study regression for identifying the factors sample. The model included all the predicting different satisfaction dimensions previously studied patient characteristics 
(age, education, occupation, residence, less satisfied by about 1.5 points, while parity and waiting time) as independent information and counseling dimension was factors for assessing satisfaction. As for inversely related with education and technical dimension, education was the number of visits $(B=-0.98$ and -0.39 , only significant predicting factor as the respectively). Waiting time was inversely patient with higher level of education related with constellation beside the recorded more satisfaction score by about females' residence. Regarding the total 1.7, while age was the only predicting satisfaction in general, the main predicting factor for patient satisfaction at continuity of factors were age and waiting time where care mechanisms where satisfaction score increased age by one year was decreased by about 0.14 for each one year accompanied with decreased satisfaction advancement in age. Regarding score by 0.26 , while the increased waiting interpersonal aspects of antenatal care time was followed by decreased received, the non employed persons were satisfaction score by 0.07 . 
Table 6: stepwise linear regression for defining the factors affecting different satisfaction dimensions and the total satisfaction score of the study sample.

\begin{tabular}{lccccc}
\hline \multicolumn{1}{c}{ Factors } & Beta (B) & SE & Standardized B & t & P \\
\hline Technical & & & & & \\
Constant & 15.21 & 1.71 & & 8.90 & $0.000^{*}$ \\
$\quad$ Education & 1.71 & 0.81 & 0.12 & 2.11 & $0.036^{*}$ \\
$\begin{array}{l}\text { Continuity } \\
\text { Constant }\end{array}$ & 25.02 & 1.39 & & & \\
Age & -0.14 & 0.05 & -0.17 & -2.97 & $0.003^{*}$ \\
Inter & & & & & \\
Constant & 24.28 & 0.66 & & 36.82 & $0.000^{*}$ \\
Occupation & -1.44 & 0.63 & -0.13 & -2.30 & $0.022^{*}$ \\
Information & & & & & \\
Constant & 6.69 & 0.76 & & 8.81 & $0.000^{*}$ \\
Education & -0.98 & 0.29 & -0.20 & -3.39 & $0.001^{*}$ \\
Number of AN visits & -0.39 & 0.19 & -0.12 & -2.04 & $0.043^{*}$ \\
Constellation & & & & & \\
Constant & 47.92 & 2.03 & & 23.65 & $0.000^{*}$ \\
Waiting time in minutes & -0.08 & 0.01 & -0.43 & -8.16 & $0.000^{*}$ \\
Residence & 3.23 & 1.04 & 0.16 & 3.10 & $0.002^{*}$ \\
Grand total satisfaction & & & & & \\
Constant & 122.36 & 5.11 & & 23.93 & $0.000^{*}$ \\
Age & -0.26 & 0.10 & -0.16 & -2.71 & $0.007^{*}$ \\
Waiting time in minutes & -0.07 & 0.03 & -0.15 & -2.55 & $0.011^{*}$ \\
\hline \hline Beta:regression coefficient & & & & & \\
\hline
\end{tabular}

Beta: regression coefficient

Standardized B: standardized regression co efficient

SE: Standard error

${ }^{*} P<0.05$ (significant)

\section{DISCUSSION}

This study was conducted to assess ventilated waiting area due to lack of proper quality of antenatal care services at family structure. The findings concur with another health units. Regarding the structure of care, study in Istanbul. ${ }^{(24)}$ In the present study, some poor provision of ANC was identified at all health units had shortage of vital equipments health units. Pregnant women had to wait in a and supplies for providing ANC like crowded uncomfortable and badly sphygmomanometer and reagents for 
hemoglobin testing, urine testing, ANC drugs (e.g. iron). In addition, there was inconsistent availability of the supplies, which resulted in dissatisfaction of some women. These findings were identified in other studies. ${ }^{(25,26)}$ In agreement with the findings of the current study, studies in other countries ${ }^{(27,28)}$ revealed that the quality of ANC in most public health facilities is affected by lack of necessary equipments and resources compared to private facilities mainly due to inadequate funding. This finding implied that the women were denied of services requiring materials which were not available.

Regarding the process of care, there are two simple preventive interventions that have proven effective in reducing maternal and neonatal deaths. ${ }^{(4)}$ The first intervention is tetanus toxoid, which helps to prevent neonatal and maternal tetanus. ${ }^{(29)}$ The second intervention is iron and folate supplementation which helps to prevent iron deficiency. ${ }^{(29)}$ In the current study provision of prophylactic iron sulphate, folic acid and tetanus toxoid were not done for $25.5 \%$ of women. Moreover, about one fourth of women (25.3\%) had poor level of satisfaction with drugs and supplies at different units. So, managers and decision makers should properly manage the resources of the units to guarantee regular supply. In the current study, no woman was examined for oedma, this causes serious concern as oedema is often the only clinical sign of pre-eclampsia. ${ }^{(30)}$ The staff providing ANC did not concentrate on important investigations like urine testing and blood testing, where checking blood haemoglobin and urine for albumin were not done for $23.9 \%$ of women. This implies that identification of pre-existing health conditions that may affect outcome of pregnancies such as anemia was not offered. Such missed opportunities should be regarded as indicators of poor quality. The reasons why health workers perform poorly and ways found to improve their performance need to be investigated. It needs to be established whether the problem is lack of knowledge, or failure to translate knowledge 
into appropriate practices by health care workers. However, the finding could be due to lack of staff orientation about importance of these investigations, and lack of resources such as lack of reagents. Inadequate staff training or lack of refresher courses to upgrade staff skills on maternal health have also been reported in some studies. ${ }^{(31,32)}$

Regarding outcome of care, $56.0 \%$ of the women had good level of satisfaction with the level of expertise of their care providers and this is similar to a study in Nigeria. ${ }^{(33)}$ Expectations of women as well as their perception of care would largely depend on pregnant women's knowledge about expected care, which may be dependent on previous experience as well as their level of education. ${ }^{(33)}$ This assertion is supported by the finding of other study which was conducted in Nigeria. ${ }^{(33)}$ Similarly in the current study, education was the significant predicting factor for technical dimension as the patients with higher level of education recorded more satisfaction score. Specifically,
$56.0 \%$ and $61.6 \%$ respectively of the women were pleased with the level of expertise of their care providers, and a significant proportion was confident of basic technical competence of their providers and this is similar to other study which was conducted in Nigeria. ${ }^{(33)}$

In the current study, more than half of the women had poor level of satisfaction with the dimension of information and counseling. One of the main goals of ANC is the provision of adequate information that is essential for maintaining and improving pregnancy outcomes. $^{(33)}$ Moreover information and communication are essential elements of health care provision. Reviews of women's experiences of maternity care highlight their importance. ${ }^{(34,35)}$ Unfortunately, the current study did not look at providers' views or reasons for perceived deficiency in information provided to some women. Approaches to improving quality of care should be based on regular quality assessments. It is suggested that much attention needs to be given to train 
on the concept of counseling, its importance, its requirements and importance of meeting women's information needs during antenatal clinic visits.

Interaction of caregivers with the clients has always been the key to high satisfaction with the service. ${ }^{(36,37)}$ In our study, $93.9 \%$ of women had 'Excellent' grade of satisfaction with interpersonal dimension of care and women had positive impression on all aspects of interpersonal relationship. These findings emphasized the fact that in a developing country setting, many women refer to high quality care as "being treated as human beings" without considering the technical aspect of quality. ${ }^{(36)}$ In recent time, the importance of continuity of care in improving the outcome of care is being realized. ${ }^{(38)}$ In the current study $50.1 \%$ had fair level of satisfaction with continuity of care dimension.

Waiting time has been reported to influence the satisfaction of clients. ${ }^{(39,40)}$ In the present study also, waiting time was linked to dissatisfaction with the services where Mean \pm
SD was $1.4 \pm 0.814$. This finding is similar to other studies in Saudi Arabia Cuba, Thailand, Argentina, Oman and Sudan. ${ }^{(40-42)}$ It is important for authorities at these units to find means of reducing the waiting time of pregnant women and this can be achieved by increasing the number of staff in each clinic to decrease workload and thus reduce waiting time.

As regards available facilities, women expressed dissatisfaction with waiting area, drugs and supply and the units toilet facilities. The waiting area and toilet facilities need to be upgraded in these centers to meet expectation of pregnant women. With relatively small-scale investments, many physical infrastructures can be upgraded to meet minimum standards. In accordance with similar studies, ${ }^{(23,24)}$ the questions used to explore women's satisfaction in general showed high level of satisfaction, despite the fact that varying proportion of women expressed concerns about some elements of quality of care. It should be noted, however, that respondents 
are often inclined to respond positively to questions on satisfaction with care received, especially when asked within clinical settings, as is systematically noted in research on perceived quality or satisfaction. This implies that caution should be entertained in interpreting our results and may be better considered in a relative rather than an absolute sense. This observation is corroborated by the disparities in the responses to the three questions used for evaluating women's overall perception of antenatal care. The percentages of women who would use the centre again $(57.1 \%)$ and those who were satisfied $(70.3 \%)$ indicate that 13.2 percent of the women expressed satisfaction although they were no longer willing to use the centre again. Some studies have blamed women's general uncritical attitude of health care as the reason for the satisfaction they often express and thus suggest that more emphasis should be placed on their expressed preferences than the absolute magnitude of expressed satisfaction.
Regarding relation between satisfaction and selected characteristics of the pregnant women, education was the only significant predicting factor of the technical dimension, while age was the only predictor of patient satisfaction at continuity of care mechanisms. Regarding interpersonal aspects of antenatal care received, the non employed persons were less satisfied; while information and counseling dimension was inversely related with education and number of visits. Waiting time was inversely related with constellation beside the females' residence. Other studies revealed that, socio-demographic factors (age, women education, and women occupation), were not associated with women satisfaction. ${ }^{(42,43)}$

\section{CONCLUSION}

The research provides indications about the areas that should be focused on to promote the quality of antenatal services in family health units, Alexandria. Findings indicated poor structure in all the family health units. By observation, $91.3 \%$ of pregnant 
women received poor care while $8.7 \%$ received fair care. Important areas that deserve consideration (areas of poor level of satisfaction) are gender of provider and availability of reminder system (100\%), the right to seek another doctor and women's involvement with decision-making with respect to care $(47.3 \%)$, information and counseling (95.1\%), waiting time (83.1\%), waiting room (83.8\%), toilet facility (83.5\%) and working days $(81.7 \%)$.

\section{RECOMMENDATIONS}

Family health units should be equipped with essential medical equipments including clinical management guidelines. Regular inservice training on management of women coming to health units and on the use of family medicine guidelines for examination and management of health professionals working in antenatal care is essential. This study has certain limitations but quality improvement is never an ending journey therefore further studies are valuable for the improvement of maternal health services.

\section{REFERENCES}

1. United Nations Development. Status of MDGs in Sudan in 2010. April. United Nation Development Report. 2010; [accessed 29/12/2011]. Available from: http://www. sd.undp.org/mdg_fact.htm

2. Abou Zahr C, Wardlaw T. Maternal Mortality in 2000: Estimates by WHO, UNICEF \& UNFPA: Department of Reproductive Health Research World Health Organization, Geneva; 2004 [accessed 3 February 2012] Available from:

http://www.who.int/whomatmortestimates2 000.pdf.

3. Carroli G, Villar J, Piagio G, Khan-Neelofur G, Gülmezoglu M, Mugford M, et al. WHO systematic review of randomized controlled trials of routine antenatal care. The Lancet. 2001; 357:1565-70.

4. Turan JM, Bulut A, Nalbant H, Ortayh, Akalin $\mathrm{AH}$. The quality of hospital based antenatal care in Instabul. Family Planning. 2006; 37 (1):47-60.

5. Villar J, Ba'aqeel H, Piaggio G, Lumbiganon P, Miguel Belizán J, Farnot $\mathrm{U}$, et al. WHO antenatal care randomised trial for the evaluation of a new model of routine antenatal care. Lancet. 2001; 357 (9268): 1551-64.

6. Malawi National Reproductive Health Service Guidelines. JHPIEGO and USAID; 2001.

7. World Health Organization. Antenatal care in developing countries. promises, achievements, and missed opportunities: an analysis of trends, levels and differentials, 1990-2001. Geneva: WHO; 2003.

8. WHO, UNICEF and UNFPA. Antenatal Care. 2002 [Accessed 4 February 2012]. Available from: http://www.who.int.

9. Egypt Demographic and Health Survey 2008, Maternal Health Care in Egypt 2010

10. Donabedian A. The quality of care: How can it be assessed? JAMA 1988;260: 1743-8. 
11. Donabedian A. The seven pillars of quality? Archives of Pathology and Laboratory Medicine 1990;121:1115-8.

12. Gilson L, Kitange $\mathrm{H}$, Teuscher $\mathrm{T}$. Assessment of process quality in Tanzanian primary care. Health Policy. 1993;26:119-39.

13. Gilson L, Magomi M, Mkangaa E. The structural quality of Tanzanian primary health facilities. Bulletin of the World Health Organization. 1995;73:105-14.

14. Haddad S, Fournier P. Quality, cost and utilisation of health services in developing countries. A longitudinal study in Zaire. Social Science and Medicine. 1995;40:743-53.

15. Aldana JM, Pieckulek $\mathrm{H}$, Al-Sabir A. Client satisfaction and quality of health care in rural Bangladesh. Bulletin of the World Health Organization. 2001; 79:5127.

16. Baltussen RMPM, Ye' Y, Haddad S, Sauerborn RS. Perceived quality of care of primary health services in Burkina Faso. Health Policy and Planning. 2002; 17:42-8.

17. Yazbeck A, Leighton $C$. Research note: Does cost recovery for curative care affect preventive care utilization? Health Policy and Planning. 1995;10:296-300.

18. Ministry of Health. Practice Guidelines For Family Physicians 2011.

19. Boller C, Wyss K, Mtasiwa D, Tanner M. Quality and comparison of antenatal care in public and private providers in the United Republic of Tanzania. Bulletin of World Health Organization. 2003; 81:11622.

20. Bruce J. Fundamental elements of the quality of care: a simple framework. Stud Fam Plann. 1990; 21 (2): 61-91.

21. Jain AK. Fertility reduction and the quality of family planning services. Stud Fam Plann 1989; 20 (1): 1-16.

22. Nigenda G, Langer A, Kuchaisit $C$, Romero M, Rojas G, Al-Osimy M, et al. Women's' opinions on antenatal care in developing countries: results of a study in Cuba, Thailand, Saudi Arabia and Argentina. BMC Public Health 2003; 3: 112.

23. Langer A, Nigenda G, Romero M, Rojas $\mathrm{G}$, Kuchaisit, Al-Osimi $M$, et al. Conceptual bases and methodology for the evaluation of women's and providers' perception of the quality of antenatal care in WHO Antenatal Care Randomised Controlled Trial. Paediatr African Journal of Reproductive Health Perinat Epidemiol. 1998; 12 (Suppl. 2): 98- 115.

24. Turan JM, Bulut A, Nalbant $H$, Ortayh, Akalin $\mathrm{AH}$. The quality of hospital based antenatal care in Instabul. Family Planning. 2006; 37(1) :49-60.

25. Safe Motherhood Project. Qualitative Needs Assessment Report Malawi: January-May; 1999.

26. World Health Organization Consultation on Maternal and Prenatal Infections. 28 November-2 December Report. WHO/MCH/91.10.WHO: Geneva, 1988.

27. Grein M, Mayhews S, Lubben MA. Framework for new approach to antenatal care. International Journal of Gynecology and Obstetrics. 2003; 80 92: 175-82.

28. Mandy $R$ Assessing quality and availability of maternal health services: Results from Kenya; 2001 [Accessed 4 February 2012]. Available from: file://C:Documents and Settings/User/Desktop/ Assessing the quality and availability of maternal health services.

29. "Focused Antenatal Care Planning and Providing Care During Pregnancy". [Accessed 4 February 2012]. Available at: www.whiteribbonalliance.org.

30. Murry CJL, Lopez AD. Mortality by cause for eight regions of the world: Global burden of disease Study. Lancet 1997; 349: 1269-76.

31. Fawcus S. A community based investigation of avoidable factors for maternal mortality in Zimbabwe. Studies 
in Family Planning. 1998; I 27 (6): 31927.

32. Banda H, Dzilankulani A. Malawi family planning and reproductive health project 2000-2005. health centre and community baseline needs assessment. Dedza District assessment Report; 2001.

33. Olufemi TO, Christianah Al, Adewale OS. Quality of Antenatal Services at the Primary Care Level in Southwest Nigeria. Afr J Reprod Health. 2008; 12(3):71-92.

34. Malata AM, Hauck Y, Monterosso L, McCaul K. Development and Evaluation of a childbirth education programme for Malawian women. Journal of Advanced Nursing. 2007; 60 (1), 67-78.

35. Boller C, Wyss K, Mtasiwa D, Tanner M. Quality and Comparison of antenatal care in Public and Private Providers in the United Republic of Tanzania. Bulletin of World Health Organization. 2003; 81:11622.

36. Tandon SD, Parillo KM, Keefer M. Hispanic women's perceptions of patientcenteredness during prenatal care: a mixed-method study. Birth. 2005; 32: 312-7.

37. Douglas S, Cervin C, Bower KN. What women expect of family physicians as maternity care providers. Can Fam Physician. 2007 May; 53: 874-9.

38. Patterson K, Logan-Sinclair P. Continuum of care and the antenatal record in rural new South Wales. Aust $\mathrm{J}$ Rural Health 2003; 11 (3): 110-5.

39. Bronfman-Pertzovsky MN, Lopez-Moreno S, Magis-Rodriguez C, MorenoAltamirano A, Rutstein S. Prenatal care at the first level of care: characteristics of providers that affect users' satisfaction. Salud Publica Mex. 2003; 45:445-54.

40. Nigenda G, Langer A, Kuchaisit C, Romero M, Rojas G, Al-Osimy M, et al. Women's opinions on antenatal care in developing countries: results of a study in Cuba, Thailand, Saudi Arabia and Argentina. BMC Public Health. 2003; 20:3-17.

41. Ghobashi M, Khandekar R. Satisfaction among expectant mothers with antenatal care services in the Musandam Region of Oman. Sultan Qaboos University Medical Journal. 2008; 8(3): 325-32.

42. Zeidan ZA, Idris. AM, Bhairy NM. Satisfaction among pregnant women towards antenatal care in public and private care clinics in Khartoum. Khartoum Medical Journal. 2011; 4 (2): $590-5$.

43. Bibha S., Maureen A, Edwin R. The role of mothers-in-law in antenatal care decision making in Nepal: a qualitative study. BMC Pregnancy and Childbirth 2010; 10:34. 